
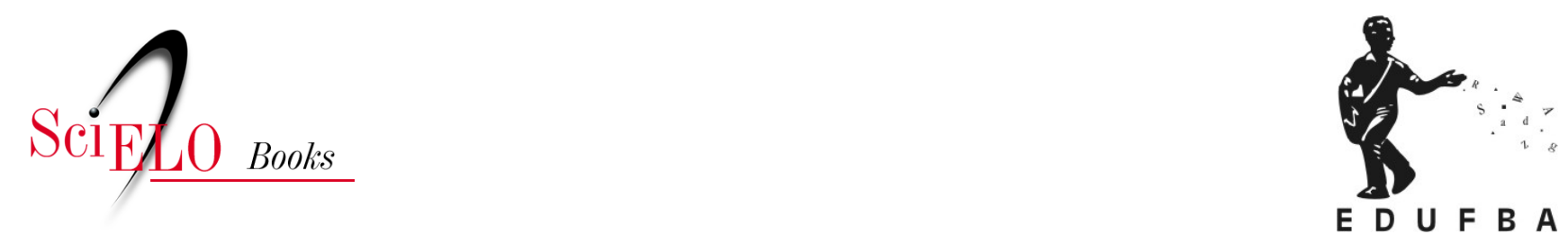

\title{
O patrimônio urbano produzido e preservado nos anos 1990
}

\author{
Marcia Sant'Anna
}

\section{SciELO Books / SciELO Livros / SciELO Libros}

SANT'ANNA, M. O patrimônio urbano produzido e preservado nos anos 1990. In: A cidade-atração: a norma de preservação de áreas centrais no Brasil dos anos 1990 [online]. Salvador: EDUFBA-PPGAU FAUFBA, 2017, pp. 395-409. ISBN: 978-85-232-1871-3.

https://doi.org/10.7476/9788523218713.0011.

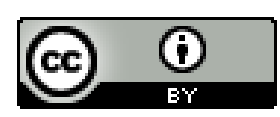

All the contents of this work, except where otherwise noted, is licensed under a Creative Commons Attribution $\underline{4.0 \text { International license. }}$

Todo o conteúdo deste trabalho, exceto quando houver ressalva, é publicado sob a licença Creative Commons Atribição 4.0. 


\section{0 patrimônio urbano produzido e preservado nos anos 1990}

\section{Os usos do patrimônio}

Nos anos 1990, as políticas de preservação do patrimônio vincularam-se a estratégias de promoção e de marketing; de desenvolvimento econômico e de atração de investimentos; de valorização imobiliária; de controle do uso do espaço público; e também, no final da década, de desenvolvimento urbano e social. Estiveram assim, em maior ou menor grau, vinculadas a apropriações distintas do patrimônio: tanto como commodity e ferramenta de controle, quanto como instrumento de política urbana e promoção social. O uso do patrimônio como recurso rentável e investimento atrativo foi grandemente promovido por incentivos fiscais e vantagens urbanísticas oferecidas pelo poder público, o que facilitou sua inserção nas mais variadas estratégias. Deu-se, contudo, de forma diferenciada segundo os agentes que participaram dessas estratégias - pequenos comerciantes ou grandes corporações, por exemplo - e conforme o maior ou menor grau de atuação do poder público em sua formulação, coordenação e execução. A conservação de espaços e equipamentos e o objetivo 
de atrair novas atividades econômicas justificaram o controle do acesso e do uso de espaços públicos nas áreas que se buscou valorizar e dinamizar, assim como o controle de usuários e ocupantes indesejáveis. As forças que comandaram essas intervenções, entretanto, a depender do nível de organização popular de cada cidade, enfrentaram resistências por parte dos que reivindicaram um uso mais democrático do patrimônio urbano. Por obra desses últimos, o patrimônio foi inserido em estratégias de desenvolvimento social e melhoria do habitat, bem como em projetos destinados à racionalização do crescimento urbano e do uso da infraestrutura instalada. Entretanto, a lógica que dominou as propostas de dinamização econômica e valorização, assim como as relacionadas ao uso habitacional do patrimônio, foi marcadamente financeira, o que dificultou, especialmente nesse segundo caso, o desenvolvimento de ações mais sistemáticas e socialmente significativas, bem como uma apropriação mais disseminada do patrimônio como instrumento de política urbana.

A despeito dos resultados - em geral, fracos - apresentados pelas estratégias de aproveitamento do patrimônio como atração urbana e elemento de valorização imobiliária, o desenvolvimento e a execução dessas estratégias imprimiram mudanças na prática de preservação num aspecto importante. A formulação, a coordenação e a execução de programas e projetos de revitalização, requalificação e reabilitação do patrimônio não foram realizadas pelos organismos ou instituições de preservação existentes nas distintas esferas do poder público, mas por instâncias responsáveis por programas de desenvolvimento econômico, execução de obras públicas, urbanização e habitação. As intervenções realizadas no período em estudo não constituíram, portanto, ações tradicionais de preservação, mas intervenções de outra ordem, que podem ser definidas como operações estratégicas no âmbito da economia, do desenvolvimento urbano e da comunicação social. Objetivos educativos e de formação cultural não foram centrais nessas intervenções, mas foi forte sua carga ideológica no sentido da construção de consensos sobre as formas, definidas como sustentáveis, de aproveitamento e reanimação de áreas de valor patrimonial. As questões preservacionistas clássicas em torno do que, como e para quem preservar saíram de cena no período, e pouco se discutiu sobre valor histórico, artístico e cultural ou, ainda, sobre a autenticidade do objeto patrimonializado. Como consequência, os organismos de 
preservação perderam prestígio, espaço e função, assim como os especialistas em patrimônio. Em contrapartida, muito se discursou sobre viabilidade econômica e financeira, sustentabilidade e valorização imobiliária. Concebidas, montadas e geridas como empreendimentos urbanos, as intervenções de preservação dos anos 1990 mobilizaram outros profissionais, como administradores, economistas, engenheiros, urbanistas, empresários da indústria cultural e publicitários.

O uso do patrimônio que, no período focalizado, apresentou concretamente os melhores resultados foi o vinculado a estratégias de marketing. Os resultados político-eleitorais e mercadológicos que intervenções de recuperação do patrimônio urbano ajudaram a propiciar foram grandes, fato que não somente impulsionou a reprodução acelerada dessas intervenções em várias cidades, mas também imprimiu contornos específicos à sua montagem. Na medida em que o resultado esperado girou muito em torno de ganhos financeiros e de imagem, intervenções e programas tenderam a perseguir objetivos imediatos, a desprezar instrumentos de conhecimento e diagnósticos aprofundados e a minimizar a necessidade de mecanismos e condições que lhes permitissem operar como ações transformadoras e produtoras de impactos econômicos e sociais positivos na situação das áreas urbanas protegidas. Por essa razão, no período em que mais se falou, se agiu e se mobilizou esforços, em todos os planos, em prol da preservação de sítios históricos urbanos, pouco se conseguiu em termos da implantação de uma política de preservação dessas áreas que propiciasse resultados duradouros e significativos.

O "patrimônio cultural" instituído pelo Estado é produto das sociedades capitalistas modernas. É um dispositivo operado pelas forças presentes no corpo social, as quais the dão, a todo o momento, sentido e utilidade. Como um dispositivo de poder, o patrimônio tem uma função política e social constitutiva e primordial, à qual sempre esteve agregada uma função econômica. A depender das forças que estão em interação em cada momento histórico, essas funções podem ser desempenhadas de modo a gerar benefícios sociais distribuídos mais amplamente, ou o dispositivo pode funcionar apenas como um agente de produção de padrões de comportamento e pensamento que favorecem uma apropriação concentrada e desigual de seus efeitos. A função social do patrimônio pode ser desempenhada de modo mais amplo, significativo e progressista quando o produto desse dispositivo informa, produz conhecimento, interroga o passado, 
atua como elemento de emancipação social e de desenvolvimento cultural e, especialmente, quando amplia noções de direito e cidadania. Quando isso não ocorre, é apenas um instrumento que propaga e mantém relações de dominação, ou seja, tem função política e social restrita.

O uso econômico do patrimônio é importante, e não necessariamente anula seus efeitos positivos. Contudo, essa apropriação econômica deve estar submetida ao cumprimento de um papel social mais abrangente e favorecer uma circulação mais ampla e democrática do patrimônio constituído no conjunto da sociedade. No que toca à herança urbana, uma circulação democrática vincula-se à possibilidade de que o sítio urbano patrimonializado exerça um papel na vida cotidiana da cidade; atue como um recurso que torna melhor o meio urbano; desenvolva um valor de uso acessível. O exercício da função social mais abrangente do patrimônio não é, portanto, incompatível com o seu uso econômico se houver o desenvolvimento de uma consciência na sociedade sobre o seu papel político maior e se os elementos por meio dos quais esse papel é desempenhado não forem apagados ou submetidos apenas a caprichos e injunções do mercado. O que impede que o dispositivo atue de modo socialmente positivo e produtivo é a transformação do seu produto em simples mercadoria ou em mero invólucro que facilita e promove um consumo para poucos.

Nos anos 1990, assistiu-se no Brasil a um uso econômico do patrimônio sem função social e educativa maior, pois, como se detalhará em seguida, foi apagada grande parte dos elementos que permitem o exercício desse papel formador e informativo. Este fato não decorreu da simples inserção do patrimônio em estratégias de valorização - mas, antes, da submissão do seu real papel a essas estratégias.

No mundo ocidental, o patrimônio é um produto histórico de sociedades capitalistas e o seu papel social sempre foi desempenhado nesse contexto, ainda que, na maior parte do tempo, com alcance restrito. Sua consolidação como recurso econômico, a partir de meados do século XX, e a expansão dessa apropriação em termos mundiais permitiram que se tornasse, finalmente, objeto de apropriação e de circulação mais amplas na sociedade. O problema é que, em decorrência da excessiva mercadificação desse recurso, isso tem se processado com destruição de conteúdo e concentração de benefícios, o que pode ser evitado se a sociedade se organizar para defender o contrário. 
O que se assistiu nos anos 1990 não foi, certamente, o fim do patrimônio, nem mesmo o anúncio da impossibilidade de sua preservação. O que ocorreu naquele momento foi apenas produto das forças políticas, sociais e econômicas que estavam em interação e apenas mais um episódio da trajetória de uma prática histórica, que, como tal, pode ser transformada.

\section{A noção de patrimônio}

As operações de seleção, salvaguarda, conservação e promoção de bens culturais foram, durante a década em exame, grandemente influenciadas pelos usos dados ao patrimônio e pelas estratégias econômicas e promocionais que o mobilizaram. Em termos gerais, operações de seleção e salvaguarda de novos objetos não foram muito frequentes no período. No caso das cidades de Salvador, Rio de Janeiro e São Paulo, essa diminuição de intensidade teve a ver com o fato de que o seu parque patrimonial já havia sido constituído, em termos gerais, entre os anos 1960 e 80 . Em compensação, as operações de conservação, bastante empreendidas na década, assim como os instrumentos criados para promovê-las, incentivá-las e financiá-las tornaram-se os principais indicadores das características da norma de preservação e produção de patrimônio que foi instituída no período.

De um modo geral, as operações de seleção e salvaguarda de novos imóveis ou conjuntos urbanos oscilaram entre os objetivos de reforçar e atualizar identidades urbanas e os relacionados a facilitar o acesso de municipalidades, governos estaduais e bens culturais aos programas de financiamento e aos incentivos fiscais implantados na década. No geral, o que motivou a seleção e a proteção foi menos o valor cultural, ou o reconhecimento desse valor em um objeto qualquer, e mais a possibilidade de que ele se tornasse fonte de renda e instrumento de promoção. Embora secundariamente, pesou ainda na decisão de salvaguardar, a intenção de proteger determinadas áreas dos desdobramentos de iniciativas de renovação urbana ou dos impactos promovidos por tendências de transformação do padrão de ocupação existente. 
Os programas nacionais de preservação, em decorrência das regras de elegibilidade que instituíram, funcionaram como instrumentos de indução de tombamentos na esfera federal e, consequentemente, de desvalorização de medidas estaduais e municipais equivalentes. A localização estratégica, a aparência, a ambiência produzida e, secundariamente, o potencial de uso e a problemática urbana comandaram a seleção de setores urbanos para intervenção no âmbito desses programas. Tais critérios de priorização influenciaram a proteção legal, retirando essa operação de constituição de patrimônios do registro histórico, memorial e documental privilegiado durante os anos 1980. No que toca às operações de seleção, portanto, os programas dos anos 1990 realizaram um retorno às práticas dos anos 1970, quando o valor econômico, em última análise, também orientava os critérios de escolha.

Os programas nacionais não inovaram nem promoveram alterações nas operações de salvaguarda. A apropriação do patrimônio urbano como media, commodity ou elemento de política urbana e habitacional não promoveu alterações nos instrumentos de salvaguarda existentes, embora a questão tenha sido discutida, especialmente no âmbito do Programa Monumenta. O tombamento federal permaneceu como único instrumento de salvaguarda disponível, pois não se tornou nem um entrave, nem algo essencial para a execução das intervenções programadas. O URBIS e o Monumenta foram os únicos programas que indicaram a necessidade de se rever mecanismos de proteção e gestão, sendo que apenas naquele primeiro se reivindicou a construção de instrumentos mais adaptados à preservação de objetos urbanos. O Monumenta tratou essa questão de modo desvinculado dos projetos de intervenção, e de modo muito preso a aspectos ligados, principalmente, à distribuição de funções entre as esferas públicas e privadas. As preocupações deste último programa com relação à prática de salvaguarda em vigor não se relacionaram, portanto, à adequação do instrumento de proteção à preservação de sítios urbanos, mas aos seus efeitos sobre os entes públicos e privados envolvidos na questão.

É interessante observar, entretanto, que, apesar de os programas e as intervenções analisadas não terem induzido nenhuma transformação nesse aspecto da prática, uma parte importante do funcionamento do mecanismo de salvaguarda foi profundamente atingida. Seus braços executivos, isto é, os organismos federais, 
estaduais e municipais de preservação foram esvaziados e praticamente anulados como instâncias decisórias ou de coordenação de ações. Em suma, no período estudado, as operações de salvaguarda não evoluíram nem se transformaram, em essência, mas seus efeitos foram alterados pelo esvaziamento e pela perda de prestígio dos órgãos de preservação.

As operações de conservação, por seu turno, foram influenciadas, principalmente, pela utilização dada ao patrimônio urbano e pelas estratégias que o envolveram, mas também pela qualidade da prática desenvolvida em cada cidade, nos anos 1980. Por isso, no Rio de Janeiro, as intervenções foram de melhor qualidade técnica, ainda que mantendo características semelhantes às das demais cidades. As operações de conservação caracterizaram-se pela reciclagem de edifícios e espaços públicos e sua adaptação a novos usos e atividades. Nessa empresa, foi norma a eliminação de anexos; o superaproveitamento de espaços internos e lotes; o foco na recuperação, reconstituição e valorização de fachadas principais (Fotos 67 e 68); o uso das cores dos edifícios como estratégia promocional dos setores sob intervenção (Foto 69); o ordenamento e a supervalorização da aparência do ambiente (Fotos 70 e 71). As intervenções operaram, frequentemente, com o contraste e o isolamento entre o novo e o antigo, mas também com uma ênfase obsessiva na reconstituição ou reinvenção de elementos vistos como de especial valor patrimonial, o que implicou uma produção, acima da média histórica, de pastiches (Fotos 72, 73 e 74). Predominou também uma postura de descolamento da arquitetura, nova ou antiga, do tecido urbano existente, bem como uma espécie de retorno a uma estética urbana e patrimonial modernista, baseada na monumentalidade e na introdução de objetos artísticos ou de impacto estético no espaço recuperado (Fotos 75, 76 e 77).

Essas características gerais das operações de conservação foram produzidas, principalmente, pelo uso do patrimônio como veículo de marketing, mas também pelo seu aproveitamento econômico enquanto abrigo de atividades culturais, comerciais, de serviço e residenciais. O patrimônio edilício, em seus agenciamentos internos, foi intensamente adaptado a essas atividades, sem maiores considerações ou preocupações pelas perdas de documentação arquitetônica que as adaptações pudessem causar. Além dos agenciamentos internos, relações de parcelamento, de ocupação de lotes, estratégias de separação entre 
espaço público e espaço privado e a morfologia original de logradouros públicos não constituíram elementos, de um modo geral, julgados merecedores de preservação (Fotos 78,79 e 80). O rompimento de relações morfológicas dessa natureza foi constante em quase todas as intervenções. Imperou, assim, uma concepção geral de patrimônio urbano de caráter fachadista e concentrada em poucos elementos arquitetônicos, o que foi favorecido e reforçado pela lógica financeira e promocional que presidiu a montagem das operações, bem como pela falta de compromisso que imperou com relação ao papel informativo e documental do patrimônio.

A apropriação crescente do patrimônio como commodity, ou objeto utilitário e comerciável, fortaleceu a prática de se realçar e enfatizar elementos arquitetônicos rapidamente percebidos como de valor patrimonial, assim como reforçou a postura de reconstituí-los ou recriá-los onde já não existiam, ou onde se encontravam mutilados. A noção de autenticidade - tão cara ao discurso tradicional do patrimônio - se esgarçou no período e tendeu a acompanhar as injunções do mercado, com crescimento da tendência de se patrimonializar imóveis e áreas urbanas para se aumentar o seu valor ou se conseguir acesso a financiamentos. Verificou-se, por fim, um retorno da restauração como operação corriqueira, ainda que restrita às fachadas.

No que toca ao tratamento do espaço público, as intervenções tenderam a reproduzir a estetização urbana vigente nas cidades do Primeiro Mundo - processo que, no Brasil, teve início nas "praças" e "ruas" dos shopping centers e foi marcado pela estética e pelas estratégias promocionais desses equipamentos. Buscou-se trazer para o exterior as sensações de ordem, segurança e limpeza que caracterizam esses complexos comerciais, que são os grandes concorrentes locais do comércio de rua e do sítio histórico tratado como uma atração urbana (Fotos 81, 82 e 83). Nos espaços requalificados segundo essa concepção, os referenciais de memória foram valorizados no limite e na razão direta de sua capacidade de despertar interesse, de comunicar e de gerar uma imagem positiva do lugar e de sua gestão.

Cabe ressaltar, contudo, que tanto as intervenções de dinamização econômica e valorização imobiliária como as de reabilitação para uso habitacional obedeceram 
a essas linhas gerais, no que toca à conservação. No Brasil, o aproveitamento social e econômico do patrimônio não favoreceu, assim, um maior cuidado com os elementos que possibilitam o exercício de sua função memorial e documental. Tampouco favoreceu o seu uso como fonte de informações para o desenvolvimento de tecnologias construtivas alternativas e para o resgate de ofícios antigos. Esse aproveitamento serviu, principalmente, para animar o consumo e trazer para o campo da preservação as práticas mais convencionais e limitadas da construção civil.

As práticas de conservação foram ainda grandemente induzidas pelos programas nacionais de financiamento montados na década de 1990. De um lado, como observado anteriormente, suas regras e formatos induziram à conservação de monumentos e sítios históricos de grande visibilidade nacional, e, de outro, privilegiaram áreas dotadas de vazios e grande número de ruínas. As limitações das linhas de financiamento e a ausência de um sistema adequado de subsídios para a reabilitação de imóveis antigos promoveram operações de promoção do uso habitacional baseadas num superaproveitamento do volume construído e do lote, reduzindo também a preservação dos elementos de valor patrimonial ao exterior visível das edificações. Assim, os programas nacionais e as intervenções locais realizadas nos anos 1990 se identificaram plenamente no que toca às operações de conservação e coincidiram em termos do efeito final que produziram no patrimônio construído. Uma vez que o suporte físico é o que o corporifica, as operações de conservação, em última instância, determinam o que será ou não preservado e a ideia de patrimônio que entrará em circulação mais ampla. $\mathrm{Na}$ medida em que a maioria das intervenções e programas não se apoiou em um conhecimento fino do patrimônio existente, além de prévio à realização das operações de conservação, funcionaram, ainda que involuntariamente, como instrumentos de redução dessa ideia e de produção de um patrimônio associado a poucos elementos arquitetônicos, e atrelado a uma percepção sensorial fácil e de caráter unicamente ambiental. Investigações e estudos de caráter histórico, arqueológico, arquitetônico, urbanístico ou etnográfico raramente foram usados como ferramentas de apoio às intervenções.

As intervenções de reconquista de áreas centrais promoveram o patrimônio, nos anos 1990, por meio do apoio à realização de eventos e da divulgação das 
áreas "recuperadas" ou "requalificadas" como novas atrações urbanas. Esse tipo de operação mesclou-se às operações de conservação das áreas sob intervenção e utilizou estratégias de projeto que incluíram o uso da cor, técnicas de iluminação, introdução de objetos de impacto visual, de mobiliário e de sinalização que transformaram essas áreas em ambientes familiares e em verdadeiras peças publicitárias em 3D. Essas estratégias, aliadas a usos vinculados ao turismo, ao consumo e ao lazer, permitiram que os sítios recuperados funcionassem como atrações urbanas e instrumentos de marketing do setor, da cidade e de sua administração, neste último caso, com grande sucesso. Assim, a promoção do patrimônio realizou-se, naquele período, também no registro de sua apropriação midiática e econômica, o que fez com que os bens culturais funcionassem, simultaneamente, como objeto e meio de promoção. Essas operações, aliadas às de conservação, produziram as principais visibilidades que atualizaram e concretizaram a ideia de patrimônio urbano nos anos 1990 e induziram a uma concepção de cidade-patrimônio como cidade-atração.

Intervenções locais e programas mostram, por fim, que os anos 1990 constituíram, em grande parte, uma atualização da prática de preservação baseada no uso econômico do patrimônio que foi introduzida no país nos anos 1970. Mostram também que as operações de seleção, salvaguarda, conservação e promoção realizadas nos anos 1980, ancoradas no valor histórico e documental do patrimônio e em sua apropriação como instrumento de cidadania, constituíram um hiato nesse processo maior. Esse hiato se relacionou a dois episódios circunscritos: a redemocratização do país, a partir de 1982, e a redução brusca do investimento público, em decorrência da crise econômico-financeira que acarretou a suspensão temporária dos projetos dos anos 1970. O que há de novo na norma de produção e preservação do patrimônio nos anos 1990, e que é perceptível por meio das operações realizadas no período, é sua vinculação ao uso do patrimônio como veículo de comunicação e como oportunidade para o desenvolvimento e entrada de negócios e serviços no país. A apropriação midiática está perfeitamente inserida no processo de apropriação econômica do patrimônio, pois, como visto no capítulo 1, a imagem e a ideia que a constituem se transformaram, no capitalismo avançado, 
também em mercadorias. Mercadorias que, como visto ao longo deste trabalho, têm na cultura, no patrimônio e no meio urbano importantes fontes de insumos e campos privilegiados de reprodução. Contudo, menos do que um recurso cujo valor de troca foi ampliado em função da formação de um mercado significativo, no Brasil, o patrimônio agregou, durante os anos 1990, mais valor a governos e a imagens urbanas do que a edifícios e localizações. Funcionou economicamente muito mais como instrumento de geração de imagem do que como promotor de uma mercadoria de interesse para o mercado imobiliário.

A noção de patrimônio urbano produzida na década analisada correspondeu, portanto, a tudo o que pudesse rapidamente ser identificado como antigo, adaptado a novos usos e divulgado como patrimônio. Foi construída, em grande parte, pelas operações de conservação realizadas no período, assim como pelos mecanismos e instrumentos criados ou disponibilizados para colocá-las em marcha. Restrita ao poder que um elemento tem de comunicar rápida e eficientemente sua "natureza" patrimonial, a nova concepção operou uma redução e uma estetização da ideia, ao mesmo tempo em que, paralelamente, promoveu a ampliação do território urbano submetido à lógica da preservação. Ocorreu, assim, paradoxalmente, uma redução promovida pela abundância, pelo excesso e, finalmente, pela entrada do patrimônio urbano no circuito da mercadoria. A noção de patrimônio foi, nesse processo, despojada de profundidade histórica e concentrada na superfície dos objetos (Foto 84). O patrimônio perdeu função documental e formadora, e foi usado na produção de cenários devidamente patrocinados para consumo turístico, cultural e de lazer. A preservação tornou-se - como bem observou Mesentier (1992) no início desse processo no Brasil - um novo tipo de renovação urbana, que lança mão da preservação de formas antigas. Um novo fator de homogeneização espacial, realizado por meio de operaçóes que, muitas vezes, fazem tabula rasa de processos culturais, de aspectos imateriais associados ao uso do patrimônio e de atividades existentes, que usa a herança construída para criar atrações comerciais e imobiliárias de apropriação restrita. 


\section{As transformações da prática de preservação}

A análise das intervenções nas áreas centrais de grandes cidades brasileiras e do escopo dos programas nacionais implementados nos anos 1990 mostra que essas iniciativas se inseriram num processo maior de transformação da prática de preservação, que teve início no final dos anos 1960. Transformação que, em última análise, mudou a função dominante do dispositivo de patrimônio na sociedade brasileira. Essa função deixou de ser a de produzir significados necessários à construção de uma identidade nacional, ao desenvolvimento cultural e artístico e à formação de cidadãos brasileiros para se tornar uma função de produção de valor agregado. Na década em exame, a essa nova finalidade veio também se juntar a de produzir significados para a construção de imagens públicas, urbanas e comerciais. A partir dos anos 1960, em suma, o patrimônio deixou de ser um dispositivo primordialmente voltado para a educação e o aprimoramento cultural - ainda que, a maior parte do tempo, com um viés elitista - e passou a ser um dispositivo de valorização. Seu uso como instrumento de política urbana e desenvolvimento social, inaugurado nos anos 1980, não predominou nem construiu norma no período focalizado.

As transformações na norma de preservação se implantaram com diferentes graus de rompimento ou continuidade com relação a práticas anteriores. A partir dos anos 1970, a preservação do patrimônio deixou de ser um fim em si e transformou-se em meio para se alcançar outras metas, relacionadas, no geral, à dinamização econômica. Os anos 1990 consolidaram essa tendência. Nessa última década, a vinculação da preservação ao desenvolvimento da economia urbana concentrou ações nas áreas centrais das grandes cidades, especialmente em seus núcleos dinâmicos, e nos seus sítios de maior potencial do ponto de vista do turismo, da cultura e do lazer. Houve, assim, uma tendência de se privilegiar apenas certas partes da cidade, em oposição à visão mais abrangente que predominou nos anos 1980.

Diferentemente de outras épocas, o patrimônio foi, durante os anos 1990, menos objeto de discurso e mais de intervenção. Para fazer deslanchar tais intervenções, utilizaram-se instrumentos e mecanismos velhos e novos, mas, nesse aspecto, o que marcou e diferenciou a prática, foi a busca e o uso intenso de instrumentos 
de mobilização e envolvimento de recursos privados com vistas à conservação do patrimônio. Novas modalidades de renúncia fiscal e parcerias foram montadas e surgiu como importante moeda de troca, em alguns lugares, a alteração ou a flexibilização do aparato legal. Durante os anos 1990, antigas reivindicações por compensação ou incentivo financeiro à atividade de preservação foram, finalmente, concedidas e ampliadas. Proprietários de imóveis foram, muitas vezes, premiados por terem abandonado e arruinado seu patrimônio localizado nas áreas centrais e empresários foram pesadamente incentivados a instalar novas atividades em setores recuperados pelo Estado. Contudo, a despeito desses incentivos, os resultados em termos de captação de recursos privados não foram os esperados, e a intervenção de preservação permaneceu como atividade financiada, basicamente, pelo poder público. Neste ponto, portanto, não houve transformação de monta com relação aos outros períodos da trajetória da norma de preservação do patrimônio urbano no Brasil. O Estado continuou sendo o grande formulador, coordenador, conservador e financiador dessas ações, embora o investimento público tenha sido, algumas vezes, orientado por demandas da iniciativa privada.

Apesar das muitas vantagens oferecidas para tornar atrativo o investimento em recuperação e conservação do patrimônio, a resposta do setor privado ficou muito abaixo das expectativas, em decorrência da falta de mercado consumidor significativo para o patrimônio. Centradas em metas de dinamização e de valorização imobiliária através do turismo, da cultura, do lazer e da atração de atividades produtivas contemporâneas, as intervenções realizadas em Salvador, no Rio de Janeiro e em São Paulo não se desenvolveram da forma projetada, por ausência de crescimento econômico no país, pela falta de controle sobre vetores de crescimento urbano e de investimento imobiliário e, também, por inadequação dos seus projetos às demandas locais eà realidade urbana. Esse relativo fracasso abriu campo para objetivos de maior alcance, como o provimento de unidades habitacionais para rendas médias e baixas, mas essa nova estratégia de aproveitamento do patrimônio encontrou muitos entraves e resistências, dependendo, para se firmar, da competência e da organização política dos atores mobilizados. De todo modo, configurou-se, no final da década em exame, a tendência de se equilibrar o uso comercial do patrimônio urbano com um uso social mais amplo, o que abriu perspectivas interessantes para sua inserção na vida contemporânea. 
O aproveitamento econômico expandiu o campo institucional do patrimônio, durante os anos 1990, no sentido de que mais organismos públicos e novas organizaçóes da sociedade foram envolvidos. Ao mesmo tempo, entretanto, esse campo institucional sofreu grande esvaziamento no que toca à sua esfera técnica especializada, em decorrência da precarização, esvaziamento e enfraquecimento dos organismos públicos de preservação. Nesse último aspecto houve uma transformação significativa, pois, nos anos 1970, o aproveitamento turístico e econômico do patrimônio ensejou o contrário, ou seja, o fortalecimento, a ampliação e a criação de vários organismos de preservação nos estados da federação.

A participação da sociedade na montagem e execução de políticas de preservação, através de organizações não governamentais, associações civis ou movimentos sociais, foi muito fraca, em comparação com os anos 1980, especialmente em Salvador e no Rio de Janeiro. Já em São Paulo, verificou-se tendência oposta, com a atuação constante de dois tipos de organizações. O primeiro, de defesa de interesses corporativos e de proprietários urbanos, com vistas à valorização do seu patrimônio imobiliário localizado no centro; e o segundo, de defesa de reivindicações das camadas populares por melhores condições de moradia na cidade e pela inclusão dessa questão nos projetos de requalificação, repovoamento e revitalização de áreas centrais.

A noção de patrimônio, como já observado, sofreu redução nos anos 1990, especialmente no que toca aos elementos arquitetônicos, urbanísticos e de natureza imaterial que the são associados. Em contrapartida, foram ampliadas suas fronteiras temporais e tipológicas, bem como o território associado ao parque patrimonial do país. Mais cidades, e até mesmo as que antes se orgulhavam de ser modernas, lançaram-se ao resgate e à valorização de seu legado histórico.

A década de 1990 apresentou, portanto, continuidades e rupturas com relação à prática de preservação de períodos anteriores, mas constituiu, essencialmente, um momento mais recente de desenvolvimento do processo de aproveitamento econômico do patrimônio que foi iniciado no final dos anos 1960 . Essa década propiciou, contudo, as condições para um novo embate de forças, que poderá conduzir, no futuro, a uma nova reestruturação do dispositivo de patrimonialização, desta vez, mais voltada ao uso do patrimônio como instrumento de política urbana e desenvolvimento social. Após vários anos de oferecimento 
intenso ao mercado, na falta deste surgiram perspectivas para a inserção da herança urbana em novos contextos.

A cidade histórica brasileira concebida, em outras épocas, como monumento artístico e como documento histórico da nação, terminou o século XX apropriada como mais uma atração do cenário urbano. O patrimônio preservado nos anos 1990 foi, então, aquele produzido no âmbito e na perspectiva dessa "cidade-atração". 